\title{
Adaptive modification of lip and its associated structures of Hill- stream fish Schizothorax richardsonii (Cypriniformes: Cyprinidae).
}

\author{
Hoshiyar Singh ${ }^{1}$, S.C. Joshi ${ }^{2}$, Ila Bisht ${ }^{1}$ and S.K. Agarwal ${ }^{1}$ \\ 1. Department of Zoology, S.S.J. Campus Almora, Kumaun University Nainital, 263601, India. \\ 2. Department of Zoology, Surajmal Agarwal Girls, P.G. College Kichha, K.U. Nainital, 263145.
}

\begin{abstract}
The lips and associated structures, in different groups of fishes, are greatly modified in relation to the characteristic mode of feeding, food preference and the mode of life exhibited by the fish. The successful maintenance of fish populations in challenging environments requires responsive adjustments in their behaviour, morphology and physiology and these have been reflected by modifications at the level of their organ systems, organs and tissues. The lips are no exception to this. The importance of food in daily life of a fish is obvious and is reflected in the form of the mouth, lips, jaw and so on. These structures present more diverse modifications than any other organ of the body. The functional aspects of the lips and associated structures in family Gobiidae, Cobitidae, Belontiidae and few species of Cyprinidae show considerable variation and exhibit unique morphological modifications associated with their lips and other structures around the mouth regarding information on the level of surface architecture as seen under SEM in relation to various food and feeding habits and ecological niches.
\end{abstract}

Key words: Cyprinidae, fishes, lip and morphology.

\section{Introduction}

Schizothorax richardsonii ${ }^{[1]}$ belongs to the family Cyprinidae, order Cyprinidiformes and sub-order Cyprinoidae. It is a hill stream fish and is predominantly adapted to life in swift flowing waters. Fish is very well adapted to the fast flowing or torrential streams having heterogeneous substrate. Mouth is inferior with fleshy lips, cone-shaped and blunt. River beds comparing mainly rocks, boulders, stones and gravel form a useful hiding and anchoring substratum for the fish. The lips are associated structures represented a significant vertebrate innovation and are highly diversified. Many Himalayan fishes have developed a unique morphological specialization in the form of an adhesive organ to maintain their station in the strong water currents. Lips may be associated with a specialized adhesive pad or modified as an oral sucker which provides an admirable device for the adhesion of fish to the substratum ${ }^{[2], ~[3], ~[4], ~[5], ~[6], ~[7], ~[8], ~[9], ~[10], ~[11] ~}$.

The gross and fine structure of the lips, the rostral caps and the horny jaw sheath is externally varied. This involves, among other things, formation of tubercles, unculi, papillae, or ridges and grooves of variable height and distribution on the lips, and the rostral cap and sharp cutting edge, cone shaped structure or unculi on the horny jaw sheaths.

\section{Material and methods}

Live adult specimen of S. richardsonii (Approximate Length 9-14 cm.) was collected from Kosi River at Hawalbagh district Almora. Water current was very fast having velocity 0.5 to $2.0 \mathrm{~m} / \mathrm{sec} .{ }^{[12]}$. To study the details of the morphological adaptations in some fishes, SEM was done. The following procedure was adopted for the preparation of specimen for SEM.

Specimen was maintained in laboratory at $25 \pm 2^{0} \mathrm{C}$. The fishes were cold anesthetized following ${ }^{[13]}$, for SEM preparation. Sections of lip were cut with the help of sharp blade and rinsed in $70 \%$ ethanol and one change saline solution to remove debris and fixed in $3 \%$ Glutaraldehyde in $0.1 \mathrm{M}$ phosphate buffer at $\mathrm{pH} 7.4$ over night at $4^{0} \mathrm{C}$ at refrigerator. The tissues were washed 2-3 changes in phosphate buffer and dehydrated in ascending series of ice cold Acetone(30\%, 50\%, 70\%, 90\% and 100\% approximate 20-30min.) and critical point dried, using critical point dryer (BIO-RAD England) with liquid carbon dioxide as the transitional fluid. Tissues were glued to stubs, using conductive silver preparation (Eltecks, Corporation, India) coated with gold using a sputter coater (JFC 1600) and examined in a scanning electron microscope (JEOL, JSM- 6610 LV) and the images were observed on the screen. 


\section{Results}

The dorsal side of the upper lip is associated with the rostral cap through a thin and extensive fold of skin, which lies in a deep groove (Fig.1), the rostral cap is greatly enlarged. The surface of the rostral cap may be divided into two distinct regions- a major proximal region towards the dorsal head skin and a narrow distal region towards the mouth opening (Fig.1).

The distal region of the rostral cap, bordering the mouth opening, is differentiated into both mucogenic and keratinized areas (fig.2 and 3). The rostral cap has a proximal mucogenic region and a distal keratinized region. At the mucogenic regions of the rostral cap the surface of the epithelial cells is characterized by well developed microridges, which reflect their high secretory activity (fig.4).

In this fish, the upper lip is clearly divided into two regions anterior and posterior, the anterior region surround the mouth opening of the fish. The anterior region of the upper lip has much small and large number of tubercles with different shape and size such as spherical, cylindrical and elongated shown in fig. 5 and 6. Each tubercle bears numerous glandular secretive device and possibly keratinized spine (Fig.7 and 8). In the upper lip numerous continuous pores or pits are present forming honeycomb-like structure with scattered round shaped sensory vesicles having slight projection. The vesicles bear groups of cilia that are mechano-sensory in function (Fig. 9). The bunch of mechano-sensory cilia (fig.10) covered in gelatinous sheath come out from these vesicles. Separate elongated mechano-sensory cilia are also shown in Fig.11.

The middle part of lower lip becomes cartilaginous and its anterior margin is turned into very sharp, horny blade like that seems to be deposition of calcium phosphate shown in the fig. 12 and 13 . This sharp blade is attached with cartilaginous part by a cemented thin strip, providing support to the sharp ridge or blade shown in the fig. 14 and 15. All these structural and functional modifications help the fish to stay in the fast flowing stream.

Callus part possess epithelial cells which are appear overlapping to each other and the boundary between the adjacent epithelial cells is delineated either by shallow separating, clefts or by a double row of microridges separated by the distinct spaces. Epithelial cells exhibit a close meshed reticular pattern shown in fig. 16 and 17. The callus part is drawn and a cavity is produced that is surrounded by the tuberculated borders. Fish scraps its food from the stone, cobbles or gravel surface with the help of this cartilaginous lower lip. The lower lip on its ventral side is associated with a specialized structure the tuberculated adhesive pad through a thin fold of skin. The adhesive pad is characteristically large and arched structure that appears like a shallow plate divided into a central region and a relatively wide peripheral region shown in the fig.18. Adhesion results due to friction between tubercles and surface of substratum.

\section{Discussion}

The upper and lower lips are associated with a greatly enlarged rostral cap and an adhesive pad, respectively. The epithelia of the lips, rostral cap and adhesive pad of the S. richardsonii reflect adaptive features which are primarily significant with respect to food preference and feeding behaviour. The upper lip and the lower lip are inconspicuous and remain concealed in a deep cleft between the HUJS(horny upper jaw sheath) and the overlying greatly enlarged rostral cap and between the HLJS(horny lower jaw sheath) and the conspicuous anterior peripheral region of the adhesive pad respectively. The rostral cap is probably present in most fish species, although it may be so reduced as to be overlooked easily. In many forms it lies well above the upper lip and plays no direct role in feeding, while in others it is greatly enlarged, partially or completely overlies the upper lip and plays a major role in gathering food from the substrate. In the older literature the rostral cap and horny jaw sheaths frequently are confused with the lips. ${ }^{[8]}$ reported that in some cyprinoids the rostral cap is greatly enlarged and partially or completely overlies the upper lip. Further, one or both lips may regress or fail entirely to develop. ${ }^{[8]}$ grossly shows the difference of the morphology of lips and associated structure such as the rostral cap, jaws, unculi (horny projection from a single cell) on the rostral cap, lips and horny jaw sheath in Cyprinidae. But as mentioned by ${ }^{[8]}$, the rostral cap and horny jaw sheath are frequently mixed with the upper lip in the classification of Cyprinidae. ${ }^{[14]}$ also stated that rostral fold (e.g. rostral cap) originates in cyprinids as a simple transverse crease in the flesh covering the maxillary bone; whereas in Labeine group (mostly equal to Labeoninae) it grows down to completely overlie the premaxillary. This cap can be seen in Parasinilabeo and its taxonomically related groups ${ }^{[15]}$.

The major proximal portion of the rostral cap and the major central region of the adhesive pad are mucogenic. The mucus may lubricate the surface and protect the epithelia from abrasions at these regions, which are likely to be subjected to wear and tear during frequent friction and adhesion of the fish to the substrate. For adhesion to the substratum, the mechano-sensory cilia of neuromuscular organ probably come in contact first with the bottom and then the tuberculated part. During adhesion sharp cartilaginous blade scraps the algal matter or scum from the stones, pebbles or cobbles. The surface may be sensed by mechano-sensory cilia in the pits of upper lip. After that the posterior free labial strip bearing tubercles comes in contact with the clean 
surface and the mucous pores secrete the mucous which immediately spreads on other pits making a firm hold in rapidly flowing waters. Upper lip bears scattered sensory organ and is involved more actively in feeding. Function of the callous portion is also under the control of the muscle. In the absence of muscles in the border, it can surmise that it acts under some reflex control. To summaries, adhesion is performed suctorially by the callous portion of the disc while the lips, postero-lateral border of the disc and the paired fins have only a frictional function. The snout and the thorax play a minor role only. When the fish detaches itself, it first releases the border from the substratum, and relaxes the muscle underlying the callous portion. Thus, the vacuum produced at the time of adhesion is disturbed and the fish swims away ${ }^{[4]}$. The crescent furrow above the adhesive disc and the specialized globular structure on the crescent's margin, can be used to regulate the pressure gradient during the anchorage of fish to the substratum. ${ }^{[16],[17],[18]}$ the lips are thrust against the substratum by the contraction of cranial muscles. ${ }^{[1]}$ studied the development of adhesive disc in Garra and stated that the true lips are only visible in the young states in the development of the fish and they are much reduced in the older. In the later case, they are covered by secondary folds, the anterior and the posterior labial folds, which have been termed the upper and lower lips respectively. ${ }^{[8]}$ observed that the so-called lips and post labial adhesive disc of Garra are frequently scored or scratched, presumably as a consequence of hard rubbing against rough substrate. The adhesive disc is capable of generating formidable sticking force if applied against the substratum and pressed carefully to create a vacuum by draining the underlying water. The intensity of this force is directly proportional to the vacuum created ${ }^{[19]}$. The free surface of the epithelial cells at different locations (e.g., skin, lips, mouth cavity and gills) of different fishes, is characteristically differentiated into series of microridges, and referred to as cytoplasmic folds, microvilli, microfolds, microvillar ridges, ridges or microridges ${ }^{[20]}$.

\section{Conclusion}

This study indicates the development of acute gustatory function, an adaptation to the peculiar mode of life of hill stream fishes. The fish studies are characterized by the peculiar trophic niche they occupy: many scrape epilithic or epiphytic algae and other food items from submerged substrates. This specialized feeding type is possible thanks to the remarkably formed, ventrally placed sucker mouth of some hill-stream fishes that allows itself to attach to a surface while scraping and eating the food attached to it. In spite of this highly specialized feeding apparatus, diversity in both thickness of the different regions of lips and in shape of lips exists and these fishes actually feed on a broad range of food. As such, Cyprinidae are the most specialized and successful fish family within the order Cypriniformes.

\section{Acknowledgement}

The authors are grateful to the Department of College of Veterinary \& Animal Sciences, G. B. Pant University of Agriculture \& Technology, Pant Nagar (U.K.), for providing necessary instruments for this research work. Thanks are also due to Mr. M. P. Singh, for his technical support.

\section{References}

[1] S. L. Hora, Ecology, Bionomies and evolution of the torrential fauna, with special reference to the organs of attachment, Phil. Trans. Royal. Soc. Lond. (B), 218, 1930, 171-282.

[2] S. L. Hora, Indian cyprinoid fishes belonging to the genus Garra, with notes on related species from other countries, Rec. Indian Mus., 22, 1921, 635-648.

[3] S. L. Hora, Structural modifications in the fish of mountain torrents, Rec. Indian Mus. 24, 1922, 31-61.

[4] S. C. Saxena, Adhesive apparatus of a hill-stream cyprinid fish Garra mullya (Sykes), Proc. Natn. Acad. Sci. India, 25B, 1959, 205214.

[5] S. C. Saxena, Adhesive apparatus of an Indian hill-streams sisorid fish Pseudecheneis sulcatus, Copeia., 1961, $471-473$.

[6] S. C. Saxena, and M. Chandy, Adhesive apparatus in certain Indian Hill-stream fishes, J. Zool. lond., 148, 1966, $315-340$.

[7] K. C. Bose, R. R. Sen Roy and T. K. Sadhu, Studies on the so called adhesive disc of Discognathus (Garra) Modestus (Day), Res. J. Ranchi univ., 6-7, 1971, 156-159.

[8] T. R. Roberts, Unculi (horny project projections arising from single cells), an adaptive feature of the epidermis of Ostariophysan fishes, Zool. Script., 6-7, 1982, 6-7, 55-76.

[9] M. Banjamin, The oral suker of Gyrinocheilus aymonieri (Teleostei: Cypriniformes), J. Zool. lond. I B., 1986, $211-254$.

[10] J. Ojha and S. K. Singh, Functional morphology of the anchorage system and food scrapers of a hill-stream fish,Garra lamta (Ham.) (Cyprinidae, Cypriniformes), J. Fish. Biol., , 41, 1992159-161.

[11] N. Singh, N. K. Agarwal, and H. R. Singh, SEM investigations on the 'adhesive apparatus' of Garra gotyla gotyla (FamilyCyprinidae) from Garhwal himalaya. In: Singh, H. R. ed., Advances in fish biology and Fisheries. Vol.1. Delhi, Hindustan Publishing Corporation, 1994, pp. 281-291.

[12] S. D. Bhatt, and J. K. Pathak, Streams of Great Mountain are: Physiography and Physiochemistry. In: Ecology of the mountain water: Ashish publ. House N. Delhi, 1991, 43-58.

[13] A. K. Mittal and M. A. Whitear, Notes on cold anaesthesia of poikilothermes, J. Fish M. Biol., 13, 1978, 519-520.

[14] G. McG. Reid, A revision of African species of Labeo (Pisces: Cyprinidae) and a redefinition of the genus, doctoral diss., Zoologicae, J. Cramer Verlag, Braunschweig. 6, 1985, 322. 
[15] E. Zhang, Study on the morphology of lips and associated structures in the cyprinid genus Parasinilabeo, Zoologica research, 19(1), 1998, 53-58

[16] H. Al- Hussaini, On the functional morphology of the alimentary tract of some fish in relation to differences in their feeding habits: Anatomy and histology, Q. J. Microse. Sci, 90, 1949, 109-140.

[17] N. Takahasi, On the homology of the cranial muscles of the Cypriniform fishes. J. Morphol., 40, 1925, 1-110.

[18] S. Girgis, The bucco- pharyngeal feeding mechanism in the herbivorous bottom-feeding cyprinoid, Labeo horie (Cuvier), J. Morphol., 90, 1952, 317-362.

[19] K.C. Nagar, M. S. Sharma, A.K. Tripathi and R.K. Sansi, Electron Microscopic study of Adhesive organ of Garra lamta (Ham.), International Research Journal of Biological Sciences, 1(6), 2012, 43-48.

[20] T. K. Garge, V. Deepa, and A. K. Mittal, Surface architecture of the opercular epidermis and epithelium lining the inner surface of the operculum of a walling Catfish, Clarius batrachus, Jap. P. Ieth., 42(2), 1995, 181-185.

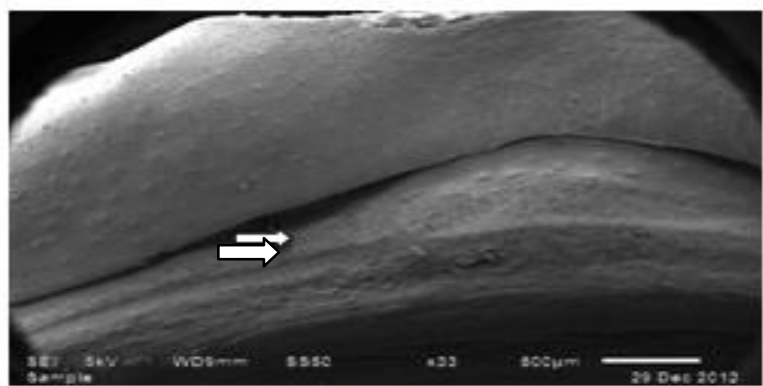

Fig.1

Fig.1 Surface electron microphotograph (SEMPH) of upper lip is associated with the rostral cap of S. richardsonii (Scale bar- $500 \mu \mathrm{m}$ ).

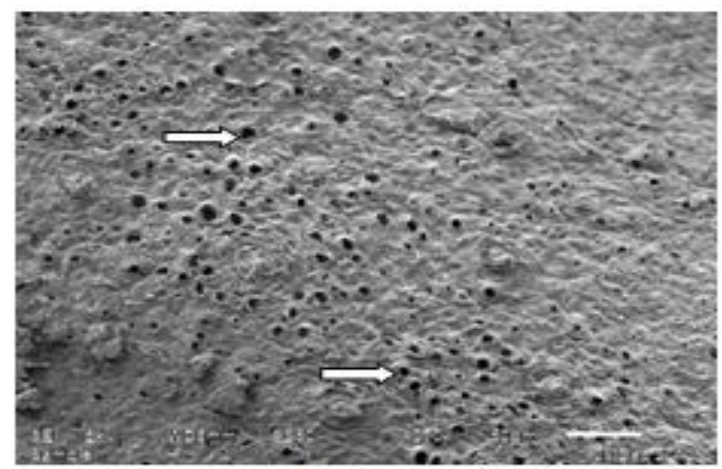

Fig. 2

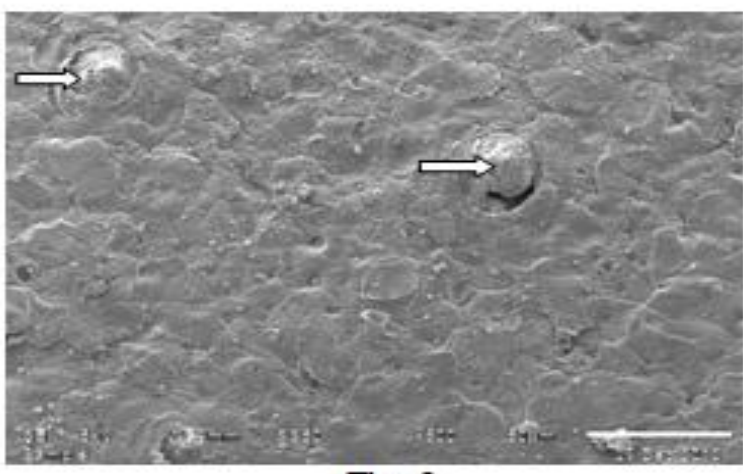

Fig. 3

Fig.2 and 3 Surface electron microphotograph (SEMPH) of the distal region of the rostral cap, bordering the mouth opering, is differentiatedinto both mucogenic and keratirized areas (Scale bar- $50 \mu \mathrm{m}$ ).

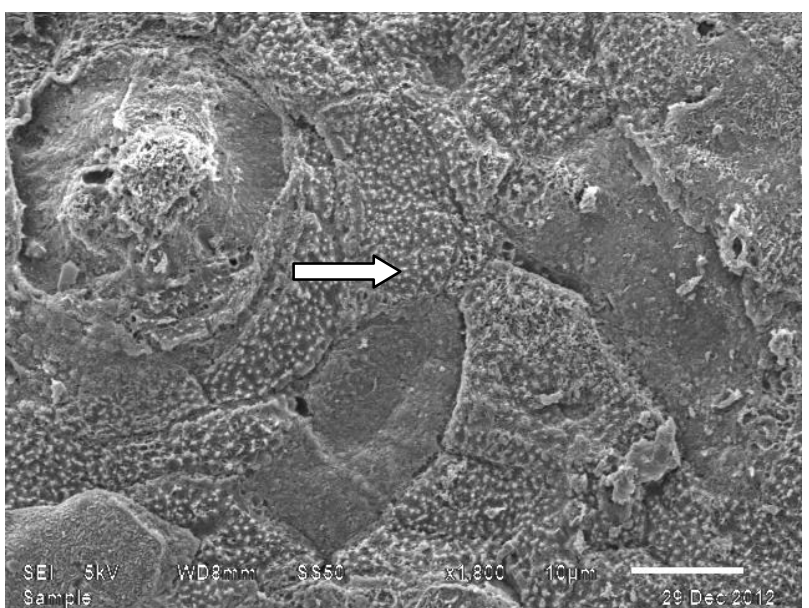

Fig.4

Fig.4 Surface electron microphotograph (SEMPH) of rostral cap showing the epithelial cells is characterized by well developed microridges (Scale bar- $10 \mu \mathrm{m}$ ). 


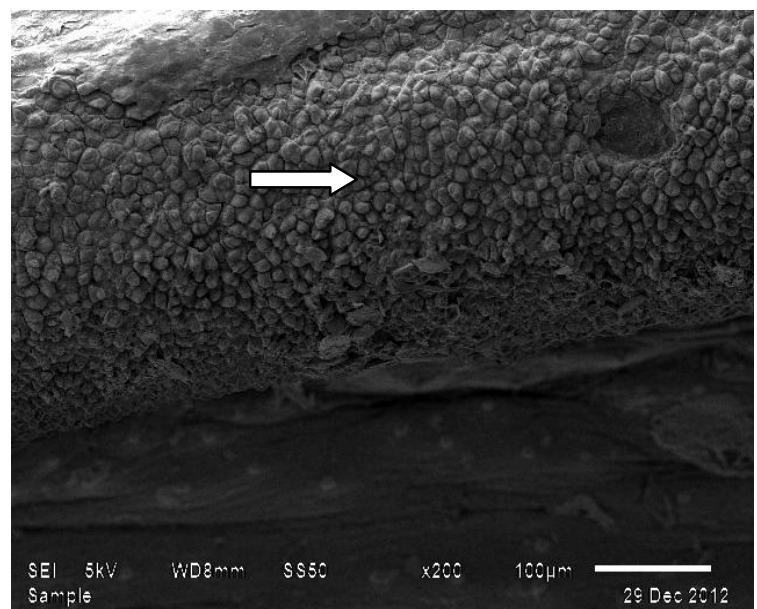

Fig. 5

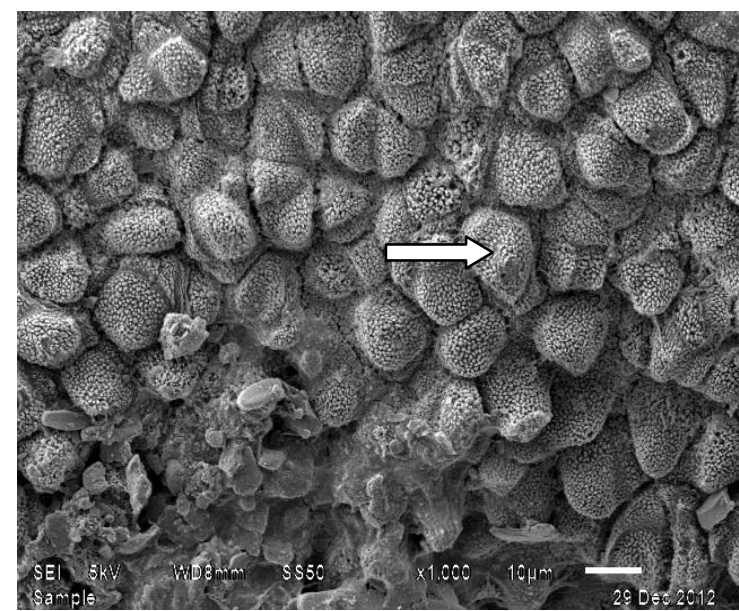

Fig. 6

Fig.5 and 6 Surface electron microphotograph (SEMPH) of the anterior region of upper lip has much small and large number of tubercles with different shape and size (Scale bar$100 \mu \mathrm{m}$ and $10 \mu \mathrm{m})$.

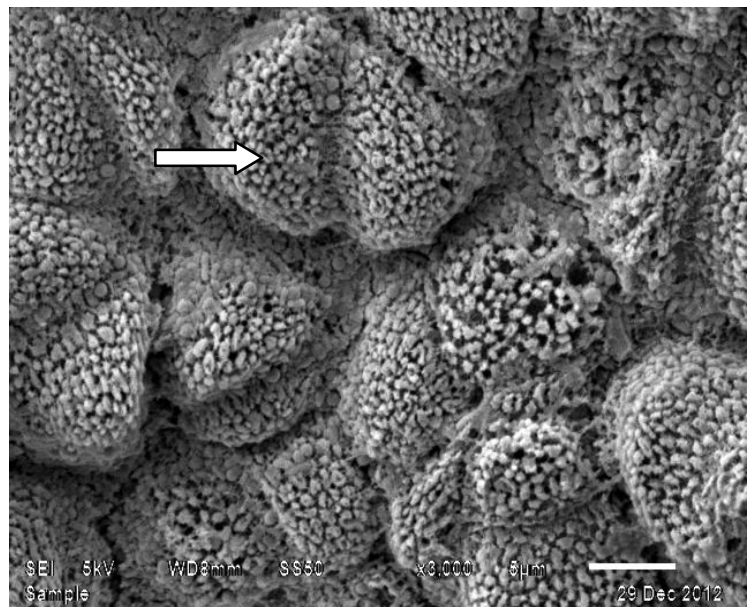

Fig. 7

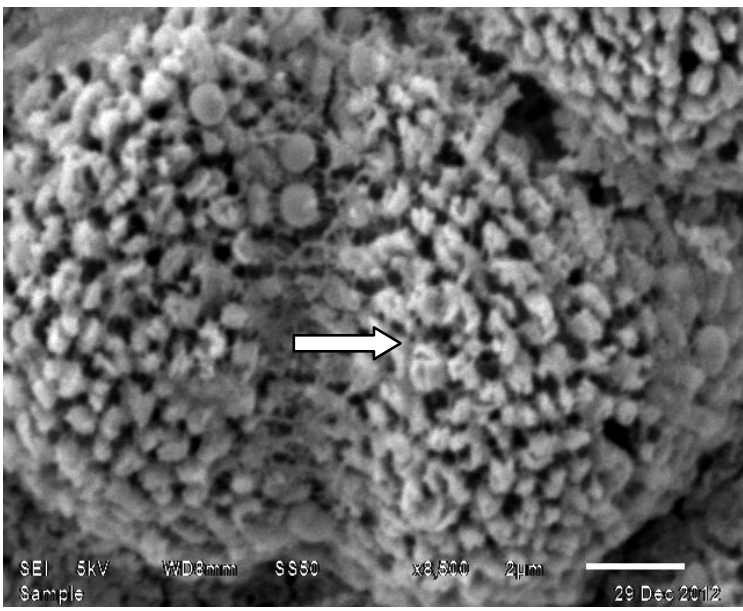

Fig. 8

Fig.7 and 8 Surface electron microphotograph (SEMPH) of the anterior region of upper lip has tubercle, which bears numerous glandular secretive device and possibly keratinized spine (Scale bar- $5 \mu \mathrm{m}$ and $2 \mu \mathrm{m}$ ).

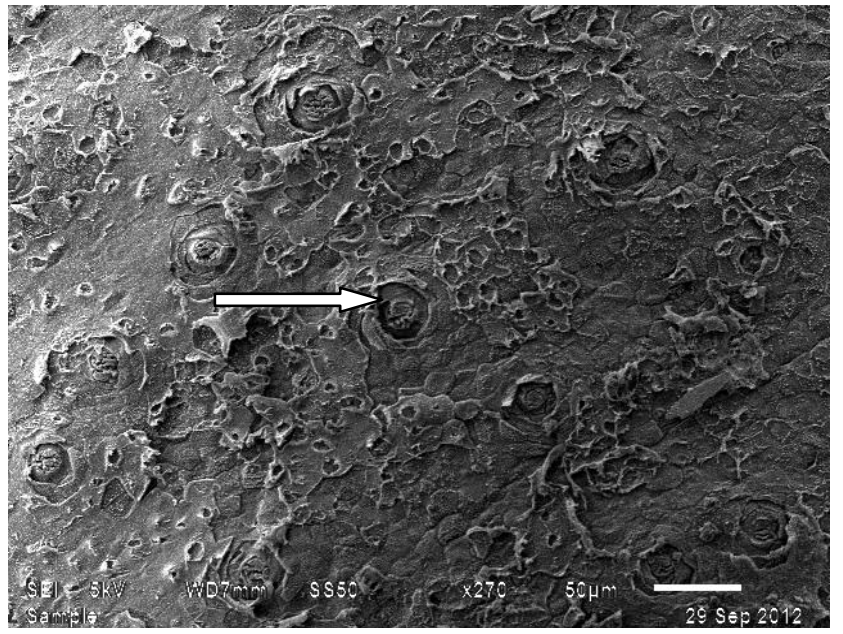

Fig.9 
Fig.9 Surface electron microphotograph (SEMPH) of the upper lip showing Honey comb-like

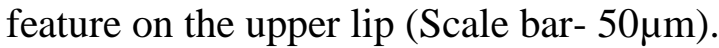

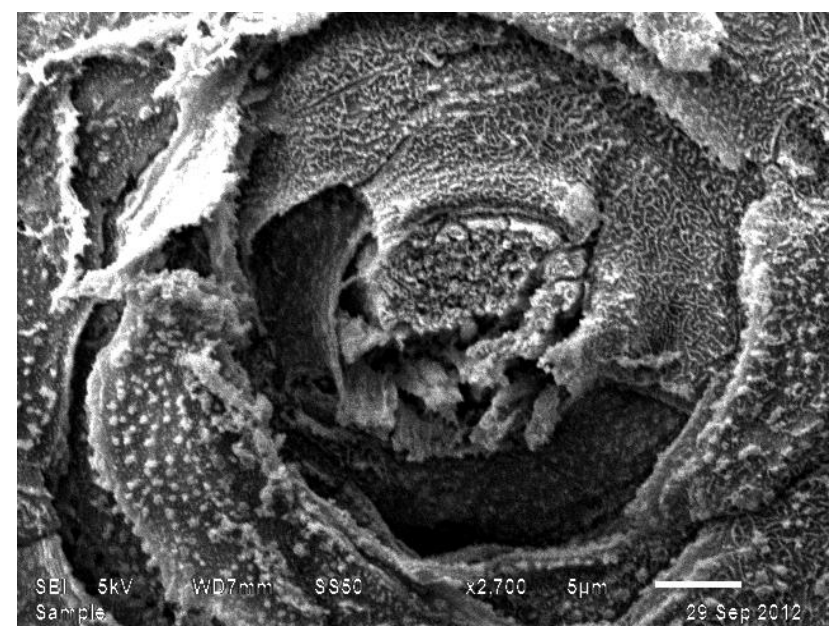

Fig. 10

Fig.10 Surface electron microphotograph (SEMPH) of the upper lip showing bunch of mechano-sensory cilia (Scale bar- $5 \mu \mathrm{m}$ ).

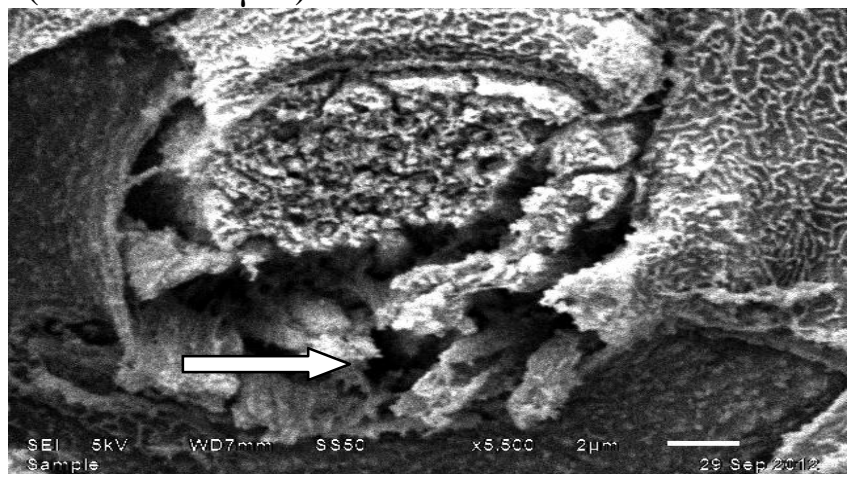

Fig. 11

Fig.11 Surface electron microphotographs (SEMPH) of the upper lip showing a bunch of mechano-sensory cilia-stereocilia (Scale bar- $2 \mu \mathrm{m}$ ).

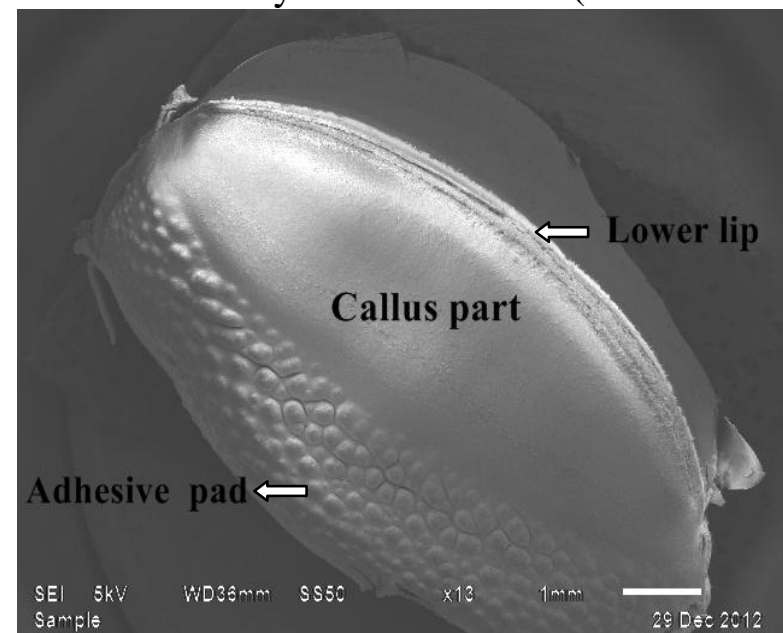

Fig. 12

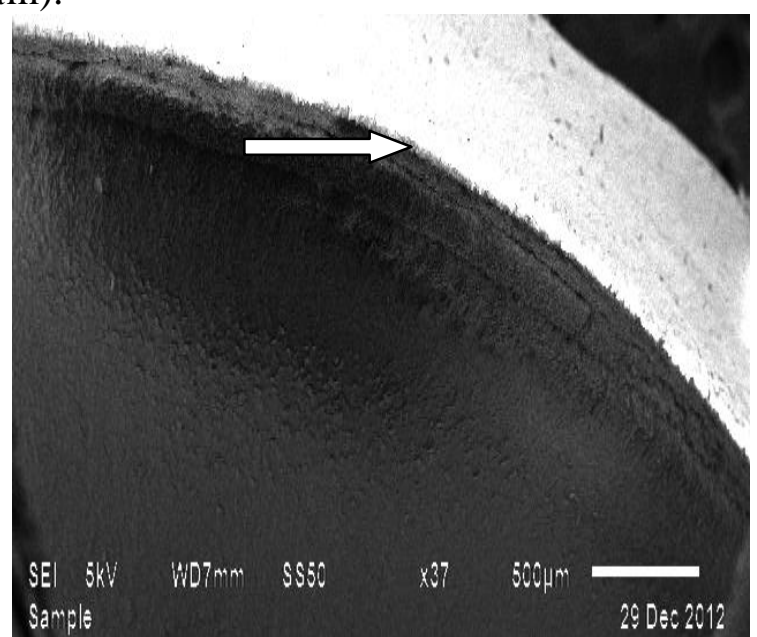

Fig. 13

Fig.12 and 13 Surface electron microphotograph (SEMPH) of the Lower lip showing is anterior margin of the lower lip is very sharp blade like and is covered with firm and hard horny cartilage (Scale bar- $1 \mathrm{~mm}$ and $500 \mu \mathrm{m})$. 


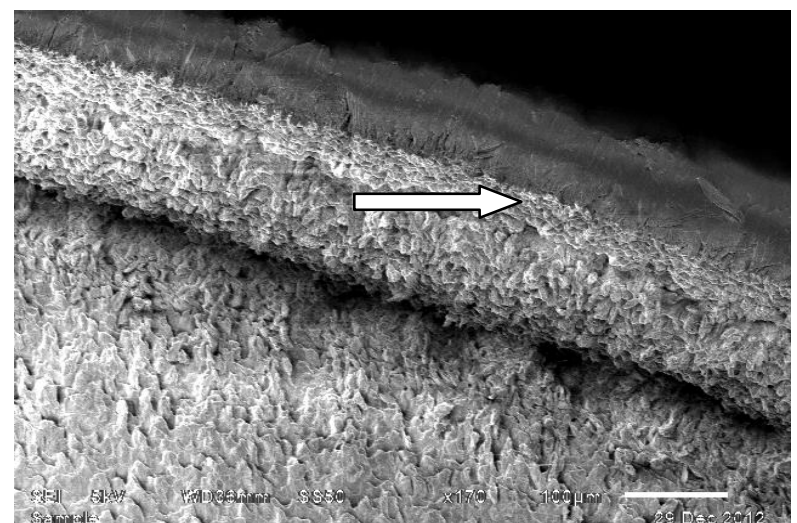

Fig. 14

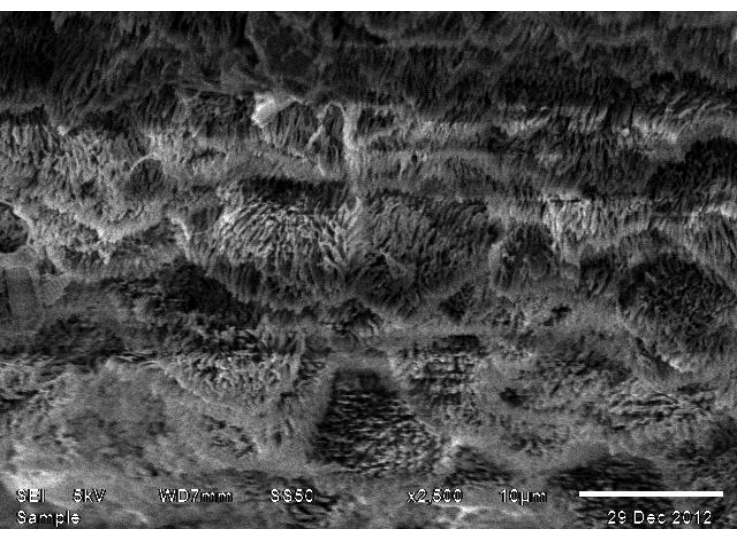

Fig. 15

Fig.14 and 15 Surface electron microphotograph (SEMPH) of the lower lip showing sharp blade is attached with cartilaginous part by a cemented thin strip, providing support to the sharp ridge or blade (Scale bar- $100 \mu \mathrm{m}$ and $10 \mu \mathrm{m})$.

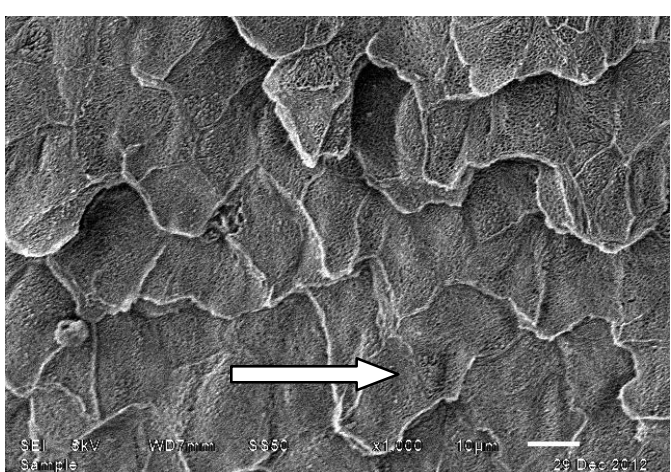

Fig. 16

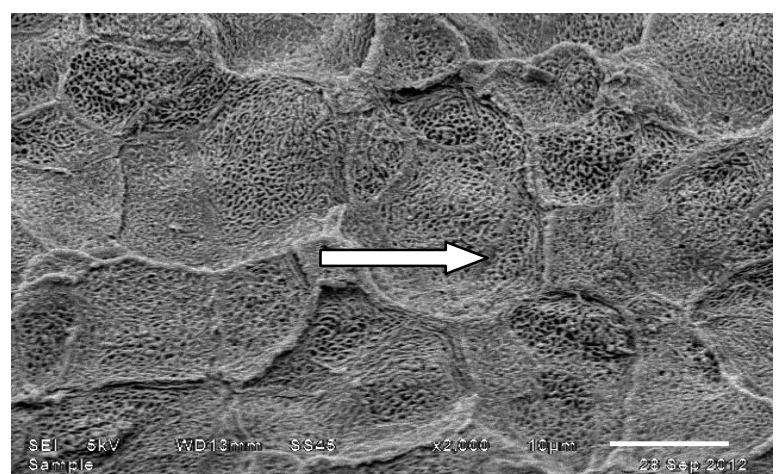

Fig. 17

Fig.16 and 17 Surface electron microphotograph (SEMPH) callus part showing epithelial cells exhibit a close meshed reticular pattern (Scale bar- $10 \mu \mathrm{m})$.

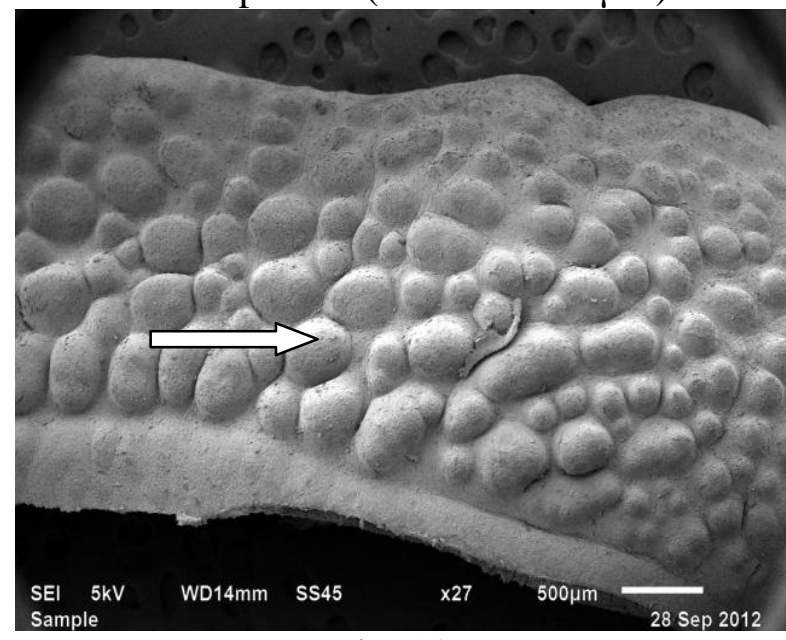

Fig. 18

Fig.18 Surface electron microphotograph (SEMPH) of the lower lip showing specialized structure the adhesive pad (Scale bar- $500 \mu \mathrm{m}$ ). 